\title{
Successful reduction of acute puerperal uterine inversion with use of Bakri postpartum balloon
}

\author{
Divya Saha*, Dipika Singh, Sarika Verma
}

Department of Obstetrics and Gynecology, ESIC Okhala, New Delhi, India

Received: 14 April 2020

Accepted: 05 May 2020

\section{*Correspondence:}

Dr. Divya Saha,

E-mail: divyagunjan111@gmail.com

Copyright: () the author(s), publisher and licensee Medip Academy. This is an open-access article distributed under the terms of the Creative Commons Attribution Non-Commercial License, which permits unrestricted non-commercial use, distribution, and reproduction in any medium, provided the original work is properly cited.

\begin{abstract}
Acute puerperal inversion is rare but potentially fatal obstetric emergency and prompt recognition will enable immediate repositioning of uterus before it becomes edematous and incarcerated. Manual repositioning along with use of uterine balloon tamponade is simple and effective way for repositioning of inverted uterus as well as prevention of recurrence.
\end{abstract}

Keywords: Bakri balloon tamponade, Inversion, Manual repositioning, Postpartum haemorrhage, Primigravida, Unbooked

\section{INTRODUCTION}

Puerperal inversion is considered to be one of the classic haemorrhagic disasters encountered in obstetric Uterine inversion is one of the causes of PPH. Uterine inversion refers to a state wherein the endometrial surface is inverted. In this condition, the uterine fundus is concave or is descending and inverted, and the inner wall of the uterus may occasionally be exposed to the inside of the vagina or to the vulva. Uterine inversion may be observed even in nonpregnant women, in cases where a tumor arising in the uterine cavity is delivered. In general, however, the term "uterine inversion" refers to puerperal uterine inversion that occurs at the time of delivery. Puerperal uterine inversion develops in the third stage of labor because of excessive traction of the umbilical cord or manual detachment of the placenta, and it is reported

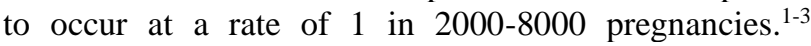
Puerperal uterine inversion is a rare condition, however, once it develops, massive hemorrhage from the surface of the detached placenta or massive atonic hemorrhage occurs, which may result in haemorrhagic shock as well as neurogenic shock. Thus, uterine inversion is a serious condition that could result in maternal death if not treated urgently. Early diagnosis and treatment are essential for the successful management of this condition; therefore, awareness regarding puerperal uterine inversion is important in daily clinical practice. Here, authors describe their experience with a case wherein acute puerperal uterine inversion caused was successfully reduced noninvasively and use of a Bakri postpartum balloon to prevent reinversion (Cook Medical Incorporated, Bloomington, IN, USA).

\section{CASE REPORT}

The patient was a 23-year-old woman primigravida who was unbooked and unregistered with just a single antenatal visit. Patient had on haemoglobin report suggestive of 6.7. She was admitted in view of primigravida with 39 weeks of gestation with anemia in labor. 2-unit packed RBC was arranged, high risk consent taken, labor was augmented with oxytocin. The delivery was completed smoothly, and she gave birth to a baby girl (weight $2300 \mathrm{~g}$; Apgar score, 9/9) without any problems.

Following the World Health Organization's recommendations, authors performed controlled cord traction. ${ }^{4}$ Placenta and membrane were delivered 
completely later within seconds of delivering placenta, fleshy mass suggestive of uterine fundus was seen exiting vaginal cavity.

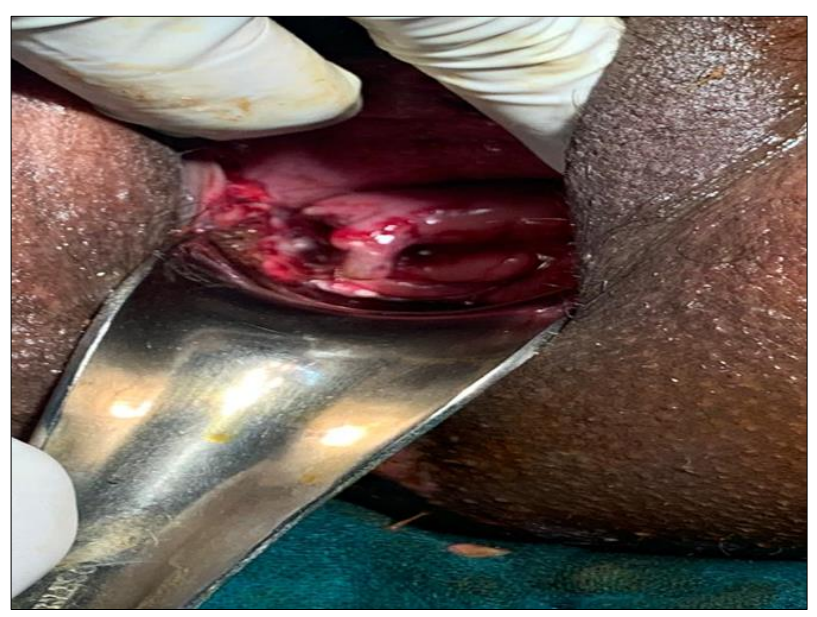

Figure 1: Day 5 postpartum.

At this time, the patient developed a state of shock, exhibiting a blood pressure of $80 / 50 \mathrm{mmHg}$, pulse rate of 130 beats/min, facial pallor. Vaginal pack was kept, immediate call for help was sent and patient was shifted to operating theatre and was prepared for general anaesthesia, thus saving time. Manual reduction of inverted uterus was attempted by fist method and by repositioning the part first that descended last that is fundus followed by body followed by lower uterine segment. Consequently, the uterus was completely reduced and was maintained in same position by bimanual compression for around 45-60 min and later Bakri balloon was inserted and inflated with $500 \mathrm{ml}$ of normal saline and the hemorrhage was stopped. Following the uterine reduction, the patient was administered oxytocic agents, injectable antibiotics, tranexamic acid, and the posttreatment course was carefully observed. No uterine reinversion was observed. Because the placement of the Bakri postpartum balloon was also useful for the prevention of reinversion, the balloon was allowed to remain in the uterus. The vagina was packed with gauze to prevent the expulsion of the Bakri postpartum balloon. The total hemorrhage volume was $3449 \mathrm{~g}$. The hematologic findings before blood transfusion were as follows: red blood cell count, $128.0 \times 104 / \mu \mathrm{L}$; hemoglobin level, $3.4 \mathrm{~g} / \mathrm{dL}$. The blood transfusion consisted of 3 units each of red blood cells and 2-unit fresh frozen plasma. On the next day. After 24 $\mathrm{hr}$ after the insertion of the Bakri postpartum balloon, the balloon was removed gradually by withdrawing $100 \mathrm{ml}$ of NS in one setting, thus in around 72 hours complete withdrawal of Bakri balloon was done. No reinversion or hemorrhage was observed. The posttreatment course was uneventful. After correction of inversion, same patient was examined on day $5^{\text {th }}$ postpartum in operating room and image has been taken (Figure 1) which depicts successful correction of inversion with normal looking cervix, while on per vaginal examination uterus was 14-
16 weeks size, postpartum state, anteverted and bilateral fornices free non tender.

\section{DISCUSSION}

Puerperal uterine inversion is an extremely rare condition, however, once it occurs, it is very likely to result in massive hemorrhage and a state of shock. Thus, it is a serious and critical obstetric condition that could result in maternal death if early appropriate treatment is not given. Hence, the decision for appropriate treatment needs to be made immediately. The presentation of puerperal uterine inversion can be acute (within 24 hours of delivery), subacute (over 24 hours and up to the 30th postpartum day), or chronic ( $>30$ days after delivery).$^{5}$

Puerperal uterine inversion may be classified as four degrees according to the stage of uterine exteriorization. ${ }^{6}$ The causes of acute puerperal uterine inversion may be endogenous or exogenous. The endogenous causes include excessive extension of the uterine wall because of placenta accreta, coiling of the umbilical cord, excessively short umbilical cord, multiple pregnancy, exceptionally large fetus, and polyhydramnios; however, these causes are rare. However, most cases of acute puerperal uterine inversion are exogenous, and the condition is often caused by external forces, such as excessive cord traction in the third stage of labor, rough Crede placental expression, and manual detachment of the placenta. The representative symptoms of acute puerperal uterine inversion are lower abdominal pain, massive hemorrhage, and shock. These typical symptoms may not be manifested when the degree of inversion is mild; therefore, if hemorrhage of unknown cause persists in the third stage of delivery, the possibility of uterine inversion should be considered.

The diagnosis of acute puerperal uterine inversion is easy if the inner surface of the uterus is exposed to the endocervical canal or the vagina. However, the presence or absence of palpability of the uterine fundus immediately after the expulsion of the placenta is useful for the diagnosis. However, if uterine inversion is suspected, ultrasonography should be performed. If "upside down, inside out," "pseudostripe" and "target sign," which indicate that the uterine fundus has dropped into the uterine cavity, are observed, a definitive diagnosis can easily be made. With regard to the treatment of acute puerperal uterine inversion, methods to rapidly improve systemic shock and simultaneously reduce the inverted uterus should be performed first. Infusion, blood transfusion, anti-shock therapy, and antidisseminated intravascular coagulation therapy should be performed to improve the systemic conditions. Noninvasive or invasive techniques can be used for the reduction of the inverted uterus. Noninvasive reduction methods, such as the use of manual or hydrostatic pressure, should be attempted first. With regard to manual reduction methods, the method described by Johnson is often used. In addition, a hydrostatic pressure 
reduction method was previously described by O’Sullivan. ${ }^{7,8}$ Recently, however, Gupta et al, reported a modified hydrostatic reduction method using transurethral resection of the prostate set to reduce failure rate. $^{9}$ In contrast, the invasive reduction methods include transvaginal operation according to Spinelli's and Kutchner's methods; transabdominal operation according to Huntington's and Haultain's methods; and simple hysterectomy. In the present case, authors have used noninvasive manual method for reposition of inverted uterus followed by bimanual compression followed by postpartum Bakri balloon insertion to prevent reinversion and prevent hemorrhage. The principle of Johnson's method is as follows: the inverted uterus is raised as much as possible to extend the uterus-supporting ligaments; subsequently, the uterus-supporting ligaments begin to contract, and the inverted uterus is reduced passively by using this contraction force. This reduction method cannot be performed with a lifted fist. The hydrostatic pressure reduction method involves the use of hydrostatic pressure that is generated when physiological saline is infused into the uterus from a higher location, in which the uterus-supporting ligaments are extended. Recent studies reported that Bakri postpartum balloon treatment is as effective as uterine artery embolization. ${ }^{10-}$ 12 Uterine inversion may often recur even when the condition is successfully reduced; therefore, the prevention of recurrence is also an important treatment goal. Various methods for preventing reinversion have recently been reported, and the placement of a Bakri postpartum balloon is an effective preventive measure against reinversion. ${ }^{13-16}$ The administration of $400 \mathrm{~mL}$ of physiological saline, as used in the present case, should produce a spherical body with a diameter of approximately $10.5 \times 8.2 \mathrm{~cm}$, therefore, the reduction may be successfully performed through pressurization of the uterus from within the uterine cavity and elevation of the uterus with this spherical body. As the number of female obstetricians has recently increased, the likelihood of these female physicians encountering cases of uterine inversion has also increased. However, a female obstetrician may lack the strength required to raise the inverted uterus with her fist.

Therefore, the use of a Bakri postpartum balloon should be extremely helpful in such cases. Rapid diagnosis and early treatment are the key factors for successfully reducing acute puerperal uterine inversion in patients. Treatment with a Bakri postpartum balloon can be performed promptly with minimal invasiveness and can yield significant hemostatic effectiveness and contribute to a rapid recovery from a state of shock. In the present case, the use of a Bakri postpartum balloon is effective for hemostasis, reduction, and the prevention of reinversion. Moreover, in cases where it is ineffective, it may be easily removed; it may also serve as a temporary option for the patient while preparations for more aggressive treatments are made. Thus, authors believe that this procedure involving a Bakri postpartum balloon may be used as a novel noninvasive reduction method for uterine inversion.

Funding: No funding sources

Conflict of interest: None declared

Ethical approval: Not required

\section{REFERENCES}

1. Platt LD, Druzin ML. Acute puerperal inversion of the uterus. Am J Obstet Gynecol. 1981;141(2):18790.

2. Shah-Hosseini R, Evrard JR. Puerperal uterine inversion. Obstet Gynecol. 1989;73(4):567-70,

3. Achanna S, Mohamed Z, Krishnan M. Puerperal uterine inversion: a report of four cases. J Obstet Gynaecol Res. 2006;32(3):341-5.

4. World Health Organization, WHO Recommendation for the Prevention and Treatment of Postpartum Haemorrhage (Guideline), WHO, 2012. Available at: http://apps.who.int/iris/bitstream/10665/75411/1/978 9241548502 eng.pdf. Accessed on 14 $4^{\text {th }}$ March 2020.

5. Livingston SL, Booker C, Kramer P, Dodson WC. Chronic uterine inversion at 14 weeks postpartum. Obstet Gynecol. 2007;109(2):555-7.

6. Cunningham FG, Gant NF, Leveno KJ, Gilstrap LC. III, Hauth JC, Wenstrom KD. Obstetric hemorrhage, in Williams Obstetrics, McGraw-Hill, New York, NY, USA, $21^{\text {nd }}$ edition; 2001:642-643.

7. Johnson AB. A new concept in the replacement of the inverted uterus and a report of nine cases. Am J Obstet Gynecol. 1949;57(3):557-62.

8. O'Sullivan JV. Acute inversion of the uterus. $\mathrm{Br}$ Med J. 1945;2(4417):282-3.

9. Gupta P, Sahu R, Huria A. Acute uterine inversion: a simple modification of hydrostatic method of treatment. Ann Med Health Sci Res. 2014;4(2):2647.

10. Doumouchtsis SK, Papageorghiou AT, Arulkumaran S. Systematic review of conservative management of postpartum hemorrhage: what to do when medical treatment fails. Obstet Gynecol Sur. 2007;62(8):5407.

11. Gronvall M, Tikkanen M, Tallberg E, Paavonen J, Stefanovic V. Use of Bakri balloon tamponade in the treatment of postpartum hemorrhage: a series of 50 cases from a tertiary teaching hospital. Acta Obstetricia et Gynecol Scandinavica. 2013;92(4):433-8, 2013.

12. Kong MCW, To WWK. Balloon tamponade for postpartum haemorrhage: case series and literature review. Hong Kong Med J. 2013;19(6):484-90.

13. Majd HS, Pilsniak A, Reginald PW. Recurrent uterine inversion: a novel treatment approach using SOS Bakri balloon. Int J Obstet Gynaecol. 2009;116(7):999-1001.

14. Keriakos R, Chaudhuri SR. Managingmajor postpartum haemorrhage following acute uterine inversion with Rusch balloon catheter. Case Reports Crit Care. 2011:Article ID 541479. 
15. Kaya B, T"uten A, Celik H, Misirlio glu M, Unal O. Noninvasive management of acute recurrent puerperal uterine inversion with Bakri postpartum balloon. Arch Gynecol Obstet. 2014;289(3):695-6.

16. Matsubara S. Combination of an intrauterine balloon and the "holding the cervix" technique for hemostasis of postpartum hemorrhage and for prophylaxis of acute recurrent uterine inversion. Acta Obstetricia et Gynecologica Scandinavica. 2014;93(3):314-5.
Cite this article as: Saha D, Singh D, Verma S. Successful reduction of acute puerperal uterine inversion with use of Bakri postpartum balloon. Int $\mathrm{J}$ Reprod Contracept Obstet Gynecol 2020;9:2591-4. 